\title{
Introducing HCI into an Organization: Making a Convincing Case for Usability
}

\author{
Gitte Lindgaard \\ Carleton University \\ Ottawa, Ontario K1S 5B6 \\ Canada \\ gitte_lindgaardecarleton.ca
}

\section{Extended Abstract}

The influence of a usability team in a particular organization and its products depends partly on the organizational structure and culture and partly on the skill set in the usability team itself. Once management decides to embrace usability, the integration of a usability team should therefore be considered very carefully in light of the existing organizational structure and culture [1,5] without, of course, neglecting consideration of the skills required to ensure the long-term benefits of usability to the organization's products.

Strategically, the three most typical usability funding models found in organizations are (a) the core corporate model, (b) a 'taxation' system, or (c) a project-by-project model. In the core corporate funding model, management has recognized the benefits and value of $\mathrm{HCI}$, and the services of the usability team are freely available for project teams. In such cases, the success of the usability team of enhancing the organization's products depends partly on the degree to which usability is integrated into the organization's product development procedures and partly on the ability of the team to deliver useful and usable results in a timely fashion. To the extent that usability is already integrated into the development process and thus presumably accepted especially by development and marketing, the usability team can concentrate entirely on providing services as defined in the development process. If, however, usability is not already firmly integrated into the development process, tension is likely to exist between usability- and project teams. In that case, usability team members typically play the dual role of constantly advocating, or 'selling', the benefits of usability to each project in a piecemeal bottom-up manner as well as delivering actual usability services. These teams are often forced to identify opportunities for collecting data with which to demonstrate the value of usability. Teams funded corporately are the least vulnerable as long as organizational restructure does not force them into either a 'taxation' model or a project-by-project model of funding.

In the 'taxation' system model the usability team is not funded corporately. Instead, each department pays a 'tax', a levy that contributes to the team's existence. To the extent that usability is well integrated into the organization's development process, this model can work well since the paying departments have already embraced and understood the necessity of including usability into their products. If, however, the usability team is not perceived to perform well, it risks being eliminated. 
Likewise, if usability is not already integral to the development process, the usability team's situation resembles that of the core corporate model in the sense that much of its work becomes piecemeal attempts to convince the rest of the organization of the value of usability. The same is true for usability teams that receive no corporate funding or a tax levy; they are the most vulnerable of all in the sense that their existence depends entirely on the degree to which they are successful at convincing individual project leaders to pay for their services. Typically, such teams are able only to perform usability tests, at least in their early days. This bottom-up introduction of usability is typical for most organizations new to usability. The relative merits, risks, and disadvantages associated with each of these models are discussed in this tutorial, aiming to give participants an opportunity to identify the model that strategically might best fit their own organization.

Regardless of the funding model adopted, usability teams must deliver more than lists of raw usability problems: problems must be translated into solutions, and the solutions must be achievable in a time- and cost-effective manner. Depending on the organization's readiness to embrace usability, the usability practitioner may also need to shape their messages so as to demonstrate the value of usability to different departments. For example, for senior management the usability message is best translated into dollars saved or dollars made [2,3,4]; for the training department, time saved in developing and administering training courses is important; for customer services, a measure of improved ease of use will be convincing. Several tools and techniques are introduced aiming to assist usability teams to select suitable tasks capable of generating appropriate data for different audiences in their efforts to demonstrate the value and cost-effectiveness of usability [6,7]. Some of the techniques discussed are applicable at the requirements analysis stage; others in the design phase and some are tied to evaluation in the pre- or post-deployment phases [4]. Practical hands-on exercises will be provided throughout this tutorial.

\section{References}

1. Hofstede, G.: Culture's Consequences: International Differences in Work Related Values. Sage Publications, Beverley Hills (1980)

2. Humburg, J., Rosenbaum, S.: Corporate strategy and usability research: a new partnership. In: Proceedings CHI'97, pp. 115-116. ACM Press, New York (1997)

3. Lindgaard, G.: Deconstructing silos: The business value of usability in the 21st Century. In: Proceedings17th. IFIP (International Federation for Information Processing) World Computer Congress, Montreal, August 25-30, pp. 3-22 (2002)

4. Lindgaard, G.: Usability testing and system evaluation: A guide for designing useful computer systems. Chapman \& Hall, London (1994)

5. Schein, E.H.: Organizational Culture and Leadership, 3rd edn. Jossey-Bass, San Francisco (2004)

6. Souza, R.: Get ROI from design. The Forrester Report (June 2001)

7. Ulwick, A.W.: Turn customer input into innovation. Harvard Business Review , 91-97 (2002) 